\title{
S-1 vs. paclitaxel plus carboplatin as adjuvant chemotherapy for completely resected stage II/IIIA non-small-cell lung cancer
}

\author{
KATSUHIRO OKUDA ${ }^{1}$, MOTOKI YANO ${ }^{1}$, TSUTOMU TATEMATSU ${ }^{1}$, KATSUMI NAKAMAE $^{2}$, \\ TAKESHI YAMADA ${ }^{3}$, TOSHIO KASUGAI ${ }^{4}$, TSUTOMU NISHIDA ${ }^{5}$, MASAAKI SANO $^{6}$, \\ SATORU MORIYAMA ${ }^{1}$, HIROSHI HANEDA ${ }^{1}$, OSAMU KAWANO ${ }^{1}$ and RYOICHI NAKANISHI ${ }^{1}$ \\ ${ }^{1}$ Department of Oncology, Immunology and Surgery, Nagoya City University Graduate School of Medical Sciences, \\ Nagoya, Aichi 467-8601; ${ }^{2}$ Department of Surgery, Nagoya West Medical Center, Nagoya, Aichi 462-8508; \\ ${ }^{3}$ Department of Surgery, Kariya Toyota General Hospital, Kariya, Aichi 448-8505; ${ }^{4}$ Department of Surgery, \\ Matsunami General Hospital, Hashima, Gifu 501-6062; ${ }^{5}$ Department of Surgery, Toyokawa Hospital, Toyokawa, \\ Aichi 442-8561; ${ }^{6}$ Department of Surgery, Nagoya Memorial Hospital, Nagoya, Aichi 468-8520, Japan
}

Received November 23, 2016; Accepted March 24, 2017

DOI: $10.3892 / \mathrm{mco} .2017 .1481$

\begin{abstract}
The majority of patients with completely resected stage II or IIIA non-small-cell lung cancer (NSCLC) require adjuvant chemotherapy to improve survival following surgery. In the present trial, the 2-year disease-free survival (DFS), and the feasibility and safety of S-1 as an adjuvant chemotherapy for advanced lung cancer were evaluated. A total of 40 patients with completely resected stage II or IIIA NSCLC were enrolled and randomized to receive postoperative chemotherapy with either up to 4 cycles of paclitaxel plus carboplatin ( $\operatorname{arm~A)}$ or with up to 1 year of S-1 (arm B). The primary endpoint was 2-year DFS. The secondary endpoints were feasibility and toxicity. A total of 40 patients were enrolled, but 3 were excluded in accordance with the exclusion criteria. The remaining 37 patients were analyzed. The 2-year DFS rate was $54.2 \%$ in arm A and $84.2 \%$ in arm B. Overall, 15/18 (83.3\%) patients completed 4 cycles of paclitaxel plus carboplatin and 13/19 (68.4\%) completed 1-year of S-1adjuvant chemotherapy. Of the 18 (16.7\%) patients in arm A, 3 experienced grade 3 or 4 adverse events, while none in arm B experienced such events. Therefore, S-1 chemotherapy for patients with completely resected stage II or IIIA NSCLC was a feasible and safe regimen, and it may therefore be considered as a potential adjuvant chemotherapy option for advanced NSCLC.
\end{abstract}

Correspondence to: Dr Katsuhiro Okuda, Department of Oncology, Immunology and Surgery, Nagoya City University Graduate School of Medical Sciences, 1 Kawasumi, Mizuho-cho, Mizuho-ku, Nagoya, Aichi 467-8601, Japan

E-mail:kokuda@med.nagoya-cu.ac.jp

Key words: non-small-cell lung cancer, adjuvant chemotherapy, carboplatin, paclitaxel, S-1

\section{Introduction}

The mortality rates of patients with non-small-cell lung cancer (NSCLC) with stage II or IIIA disease remain high. Even when complete surgical resection is performed, the 5 -year survival rate is only $54.1 \%$ in Japanese patients with pathological (P) stage IIIA disease, $47.4 \%$ for P-stage IIB and $32.8 \%$ for P-stage IIIA (1). The most frequently observed recurrence is distant metastasis. Adjuvant chemotherapy has been administered to patients with completely resected NSCLC in order to control the cancer cells and to improve patient survival. The efficacy of platinum-based adjuvant chemotherapy has been confirmed in large clinical trials (LACE) (2-4). However, the absolute improvement in the 5 -year survival rate was only $5 \%(5,6)$. Regimens including cisplatin occasionally cause severe side effects, including renal failure, deafness and gastrointestinal disorders. Furthermore, the ratio of patients who complete the treatment is insufficient, and only a $\sim 11 \%$ reduction in mortality has been achieved thus far (7-9). Carboplatin plus paclitaxel chemotherapy has been one of the most frequently used chemotherapy regimens for advanced and recurrent NSCLC (10-12), and is occasionally used as an adjuvant regimen for completely resected NSCLC $(13,14)$. Carboplatin is considered to cause milder side effects compared with cisplatin. Side effects such as neuropathy, neutropenia and thrombocytopenia prevent patients from completing a full 3 -week regimen cycle with cisplatin. Bi-weekly paclitaxel plus carboplatin has been identified as a method of reducing such side effects, while maintaining similar efficacy to the 3 -week regimen (15). This is mainly due to the fact that carboplatin rarely causes nephrotoxicity, neurotoxicity or ototoxicity, and rarely triggers emesis and thrombocytopenia, unlike cisplatin (16). In the present study, the bi-weekly carboplatin plus paclitaxel regimen was selected for adjuvant chemotherapy. The 2-year DFS with bi-weekly carboplatin plus paclitaxel in patients with stage IB-IIIB completely resected NSCLC was previously reported to be $89.0 \%$ (17). 
S-1 (Taiho Pharmaceutical Co., Ltd., Tokyo, Japan) is an oral anticancer agent comprising tegafur, 5-chloro-2, 4-dihydroxypyridine and potassium oxonate, in a molar ratio of 1:0.4:1 (18), which has achieved the highest response rate among several oral anticancer agents against unresectable advanced carcinomas in phase II studies (19). Postoperative S-1 chemotherapy is one of the standard therapies for gastric cancer in the US, Europe and Japan $(20,21)$. Several clinical trials for NSCLC using S-1 chemotherapy and S-1 + platinum-based chemotherapy have been conducted, with largely favorable findings (22-24). The mean relative dose intensity was $64.6 \%$, and grade $3 / 4$ toxicities occurred at the rate of only $15.4 \%$ over a 2 -week oral administration of S-1 followed by a 1 -week interval (24).

In the present study, the feasibility and tolerability of S-1 as adjuvant therapy for advanced lung cancer was examined.

\section{Patients and methods}

Patients. A multicenter randomized feasibility study of paclitaxel plus carboplatin vs. S-1 in patients with locally advanced completely resected NSCLC was conducted. A total of 40 patients underwent complete resection and were diagnosed with pathological stage II or IIIA NSCLC according to the 7th edition of the Tumor-Node-Metastasis classification (25) at the Nagoya City University Hospital (Nagoya, Japan) and its affiliated hospitals, between January 2008 and December 2013. Written informed consent was obtained from all the patients, and the study protocol was approved by the Institutional Review Board of each participating institution. This study was registered on the UMIN Clinical Trial database (ID:000001510).

The eligibility criteria were as follows: Histologically confirmed NSCLC, completely resected, pathological stage II or IIIA disease, no previous chemotherapy or radiotherapy, age 20-75 years, Eastern Cooperative Oncology Group performance status of 0 or 1 , white blood cell count

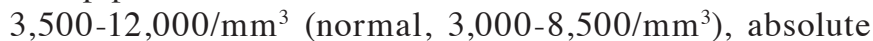
neutrophil count $\geq 2,000 / \mathrm{mm}^{3}$ (normal, 38.3-74.7\%), platelet count $\geq 100,000 / \mathrm{mm}^{3}$ (normal, 150,000-361,000/. $\mathrm{mm}^{3}$ ), hemoglobin level $\geq 10 \mathrm{~g} / \mathrm{dl}$ (normal, 10.8-14.9 g/dl), aspartate aminotransferase and creatinine level <upper limit of normal (ULN), creatinine clearance rate $>60 \mathrm{ml} / \mathrm{min}$, percutaneous oxygen saturation concentration by room air $\geq 95 \%$, and aspartate aminotransferase, alanine aminotransferase and total bilirubin levels $<2$ times the ULN; the patients also had to have started chemotherapy within 8 weeks following surgery and been able to receive oral intake. The exclusion criteria were patients with previous chemotherapy or radiotherapy, concomitant malignancy within 5 years, interstitial pneumonia with clinical symptoms, and significant cardiac arrhythmia or heart failure.

Treatment schedule. The randomization was performed centrally at the Department of Oncology, Immunology and Surgery of the Nagoya City University Graduate School of Medical Sciences (Nagoya, Japan). The patients were randomly assigned either to arm A (18 cases) receiving paclitaxel plus carboplatin bi-weekly, or to arm B (19 cases) receiving S-1. The treatments performed in the present study are schematically summarized in Fig. 1. Randomized allocation factors included facility, age, histological type and stage.

The infusing dosage of paclitaxel was $120 \mathrm{mg} / \mathrm{m}^{2}$ on days 1 and 15. Carboplatin at an area under the curve (AUC) dose of 3 was also administered on days 1 and 15 . The patients received adjuvant chemotherapy with paclitaxel plus carboplatin every 4 weeks for up to 4 cycles. The Calvert's formula was used to calculate the dose of the AUC for carboplatin (26), while the creatinine clearance was determined with the Jelliffe formula (27).

The dosage of S-1 was established as follows: Patients with a body surface area (BSA) $<1.25 \mathrm{~m}^{2}$ received $40 \mathrm{mg}$ twice daily ( $80 \mathrm{mg} /$ day); those with $\mathrm{BSA} \geq 1.25 \mathrm{~m}^{2}$ but $<1.5 \mathrm{~m}^{2}$ received $50 \mathrm{mg}$ twice daily $(100 \mathrm{mg} /$ day $)$; and those with a $\mathrm{BSA} \geq 1.5 \mathrm{~m}^{2}$ received $60 \mathrm{mg}$ twice daily (120 mg/day). S-1 was administered for 2 weeks followed by a 1-week rest period for up to 1 year. Both arms A and B continued on the above prescription unless there was any evidence of relapse, other malignancies, or severe adverse events.

Throughout the study, the dosage of paclitaxel plus carboplatin was adjusted according to the presence and severity of hematological and non-hematological toxicities. For patients exhibiting evidence of hematological or non-hematological toxicity, the treatment on day 15 was omitted and the dosage for the next course was reduced by one level (from paclitaxel $90 \mathrm{mg} \mathrm{m}^{2}$ and carboplatin AUC 2, to paclitaxel $60 \mathrm{mg} \mathrm{m}^{2}$ and carboplatin AUC 2). The dosage of S-1 was also planned to be reduced by 1 level $\left(15 \mathrm{mg} / \mathrm{m}^{2}\right)$ up to 2 times for patients exhibiting evidence of grade $\geq 3$ hematological or non-hematological toxicities. All dose reductions were limited to two levels.

Recurrence was diagnosed on the basis of imaging study findings. Chest and abdominal computed tomography and positron emission tomography plus head magnetic resonance imaging were performed at 6- and 12-month intervals, respectively. In addition, when the patients complained of any symptoms or exhibited elevated tumor markers on blood tests, imaging studies were performed.

Evaluation of feasibility and toxicity. All the eligible patients who had received any definitive treatment were considered as assessable for feasibility and toxicity. The feasibility was evaluated based on the rate of treatment completion (4 cycles completed for carboplatin plus paclitaxel, and 1 year completed for S-1) and safety (rate of grade $\geq 3$ toxicities). Adverse events were graded according to the National Cancer Institute Common Toxicity Criteria (Common Terminology Criteria for Adverse Events) version 3.0 (28).

Statistical analysis. The sample size was determined based on a phase II study reported by Kawamura et al applying docetaxel plus gemcitabine as an adjuvant chemotherapy in 35 patients (29). This previous study reported a 2 -year DFS rate of $\sim 52 \%$, with a $95 \%$ confidence interval (CI) of 35-69\%. Based on this result, the expected and threshold values of the 2-year DFS were 40 and $65 \%$, respectively. The number of patients required was determined with an $\alpha$ risk of 0.05 and a $\beta$ risk of 0.1 . The number of patients in each arm was calculated using the Fleming method and found to be 32 per arm. Sufficient data for patients in the present study could not be gathered within the study period. The primary endpoint was the 2-year 


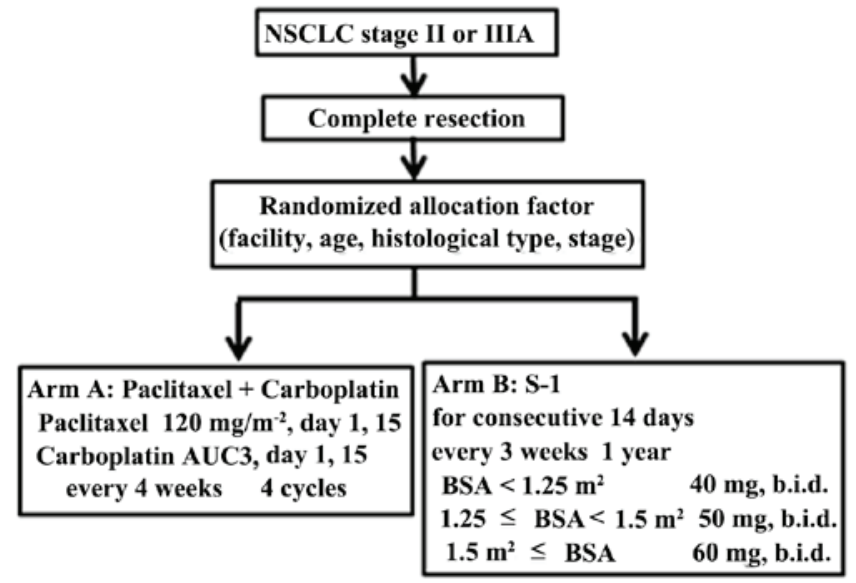

Figure 1. Treatment scheme of the present study. NSCLC, non-small-cell lung cancer; AUC, area under the curve; BSA, body surface area; b.i.d., twice daily.

DFS rate, and the secondary endpoints were the feasibility and toxicity. The characteristics, feasibility, adverse events, DFS and overall survival of 37 patients were analyzed. The cumulative total administration cycles, 2 and 5-year DFS and overall survival (OS) were examined by the Kaplan-Meier method and the difference between the two arms was calculated by the log-rank test. The differences in the rate of adverse events were evaluated by the $\chi^{2}$ test. All the data were analyzed with EZR software (30). $\mathrm{P} \leq 0.05$ was considered to indicate a statistically significant difference.

\section{Results}

Patient enrollment. A total of 40 patients with stage II or IIIA NSCLC who had received surgically complete resection were enrolled. Of the 40 patients, 3 were excluded in accordance with the exclusion criteria: 1 patient refused to continue participating in this study after registering, 1 patient used another chemotherapy regimen during the follow-up period (under recurrence-free conditions) and 1 patient had a history of multiple cancers. The remaining 37 patients were randomized to either arm (18 cases in arm A and 19 in arm B). The patient characteristics are summarized in Table I. Briefly, the patients included 6 women and 31 men, with a mean age of 62.8 years (range, 39-75 years). In arm A, 2 patients with pneumonectomy $(2 / 37,5 \%)$ were included. These 2 patients completed four cycles of carboplatin plus paclitaxel, but were confirmed to have recurrence within 1 year following surgery. When interpreting the results of the present study, this point should be kept in mind.

Treatment delivery. In total, $50 \%$ of the patients in arm A received paclitaxel plus carboplatin and $52.6 \%$ of the patients in arm B received S-1, along with the planned schedule and at the planned dose (Table II). In arm B, 1 of the 2 patients refused to continue the treatment due to financial difficulties, and the other interrupted the treatment due to continued grade 1 anorexia.

Feasibility and toxicity. The drug-related adverse events are listed in Table III. The main adverse events in arm A were anaphylaxis, hematological toxicity, neuropathy and alopecia. Two patients developed a grade 4 allergic reaction (anaphylactic shock); however, immediately after cessation of the infusion of paclitaxel, and following treatment with steroid therapy, the patients recovered without sequelae. Both patients discontinued adjuvant chemotherapy with paclitaxel plus carboplatin: 1 patient went on to receive 4 cycles of gemcitabine plus carboplatin as adjuvant therapy, and the other patient received no further adjuvant chemotherapy. There were no grade 3 or 4 adverse events in arm B. Adverse events occurred in 15 patients $(83.3 \%)$ in arm $\mathrm{A}$, and in 11 patients $(57.9 \%)$ in arm B; the difference was non-significant $(\mathrm{P}=0.151)$. In total, 3 patients $(16.7 \%)$ in arm $\mathrm{A}$ and 6 patients (31.6\%) in arm B discontinued drug administration due to adverse events caused by the agent and the patients' wishes. In addition, 6 patients (33.3\%) in arm A and $3(15.8 \%)$ in arm B required a dose reduction due to adverse events. No treatment-associated deaths occurred.

Survival. Ultimately, 9 patients (50\%) in arm A and 8 (42.1\%) in $\operatorname{arm} \mathrm{B}$ relapsed. In arm A, the relapse sites were the brain (4 cases), the brain and mediastinal lymph nodes (1 case), the bone ( 1 case), the adrenal glands ( 1 case), the mediastinum (1 case), and the mediastinum and supraclavicular lymph nodes ( 1 case). In arm B, the relapse sites were the brain and mediastinal lymph nodes ( 1 case), the trachea (1 case), the supraclavicular lymph nodes (1 case), the mediastinal lymph nodes ( 2 cases), and the intrathoracic cavity (3 cases). Two patients were excluded from the analysis of DFS and OS as they were unable to continue paclitaxel plus carboplatin chemotherapy due to an anaphylactic reaction following infusion of paclitaxel. The median follow-up time was 47 months (range, 13-79 months). The 2-year DFS rates were 54.2\% (95\% CI: $27.1-75.0 \%$ ) in arm A and 84.2\% (95\% CI: 58.7-94.6\%) in arm B (Fig. 2A). No statistically significant difference in the 2-year DFS was noted between the two arms, although there was a weak tendency toward an improved rate in arm B. For further detailed breakdowns of the effects on survival, the 5-year DFS (Fig. 2A) and OS (Fig. 2B) was also investigated.

\section{Discussion}

The survival of patients with advanced lung cancer is unfavorable compared with malignant tumors of other organs (31). However, adjuvant chemotherapy may improve the outcomes of advanced lung cancer patients who have undergone surgically complete resection.

The result of clinical trials in Japan regarding the oral administration of UFT (tegafur and uracil at a 1:4 molar ratio) demonstrated significant survival benefits for stage I patients who have undergone complete surgical resection (32). Platinum-based chemotherapy is used as standard adjuvant chemotherapy for patients with locally advanced (stage II or IIIA) disease $(3,4)$, but its treatment outcomes have been controversial $(5,6)$. Several challenges have been associated with the use of platinum-doublet adjuvant chemotherapy $(3,4)$, such as severe adverse effects, including renal failure, deafness and gastrointestinal toxicity. To reduce the rate and severity of such side effects, several adjuvant chemotherapy regimens have been proposed and evaluated in a series of clinical 
Table I. Characteristics of 37 eligible patients.

\begin{tabular}{|c|c|c|c|c|}
\hline Characteristics & All patients & PTX + CBDCA & S-1 & P-value \\
\hline Number of patients & 37 & 18 & 19 & \\
\hline \multicolumn{5}{|l|}{ Observation period, months } \\
\hline Range & $13-79$ & $17-75$ & $13-79$ & \multirow[t]{2}{*}{0.62} \\
\hline Median & 47 & 39 & 48 & \\
\hline \multicolumn{5}{|l|}{ Sex } \\
\hline Male & 31 & 14 & 17 & \multirow[t]{2}{*}{0.405} \\
\hline Female & 6 & 4 & 2 & \\
\hline \multicolumn{5}{|l|}{ Age, years } \\
\hline Range & $39-75$ & $47-73$ & $39-75$ & \multirow[t]{2}{*}{0.471} \\
\hline Mean & 62.8 & 62.8 & 62.9 & \\
\hline \multicolumn{5}{|l|}{ Histological type } \\
\hline Adenocarcinoma & 23 & 10 & 13 & \multirow[t]{3}{*}{0.379} \\
\hline Squamous cell carcinoma & 12 & 6 & 6 & \\
\hline Others & 2 & 2 & 0 & \\
\hline \multicolumn{5}{|l|}{ Pathological stage } \\
\hline IIA & 17 & 9 & 8 & \multirow[t]{3}{*}{0.98} \\
\hline IIB & 11 & 5 & 6 & \\
\hline IIIA & 9 & 4 & 5 & \\
\hline \multicolumn{5}{|l|}{ Surgery } \\
\hline RUL & 13 & 6 & 7 & \multirow[t]{6}{*}{0.702} \\
\hline RMLL & 2 & 0 & 2 & \\
\hline RLL & 9 & 4 & 5 & \\
\hline LUL & 6 & 4 & 2 & \\
\hline LLL & 5 & 2 & 3 & \\
\hline Left pneumonectomy & 2 & 2 & 0 & \\
\hline
\end{tabular}

P-values were calculated using the $\chi^{2}$ test. RUL, right upper lobectomy; RMLL, right middle and lower lobectomy; RLL, right lower lobectomy; LUL, left upper lobectomy; LLL, left lower lobectomy; PTX, paclitaxel; CBDCA, carboplatin.

trials (7-9). However, no optimal adjuvant chemotherapy has yet been established for advanced lung cancer.

At present, carboplatin doublet chemotherapy has been found to have almost the same effects as cisplatin doublet chemotherapy in the treatment of patients with recurrent and advanced lung cancer (10-12). Paclitaxel plus carboplatin is also considered a standard chemotherapy regimen for recurrent and advanced lung cancer, although several specific side effects, including anaphylactic reaction and neuropathy, may occur (11-13).

In the present study, the efficacy of orally administered S-1 was evaluated as adjuvant chemotherapy for stage II or IIIA patients who had undergone complete surgical resection of their tumors. S-1 is a fluorouracil chemotherapeutic agent used for recurrent and advanced lung cancer as second- or third-line chemotherapy. As S-1 is considered more effective compared with UFT, long-term S-1 administration may be promising as an adjuvant chemotherapy for advanced lung cancer (22). Similar to the results reported by Iwamoto et al (22), the present study found adjuvant chemotherapy with long-term $\mathrm{S}-1$ in completely resected stage II-IIIA NSCLC to be safe and effective. In the present study, S-1 therapy was compared with
Table II. Administration of treatment.

\begin{tabular}{|c|c|c|c|c|}
\hline \multirow[b]{2}{*}{ Patients } & \multicolumn{2}{|c|}{$\begin{array}{l}\text { Carboplatin }+ \\
\text { paclitaxel }\end{array}$} & \multicolumn{2}{|c|}{ S-1 } \\
\hline & No. & $\%$ & No. & $\%$ \\
\hline $\begin{array}{l}\text { Patients following planned } \\
\text { schedule and dose }\end{array}$ & 9 & 50 & 10 & 52.6 \\
\hline Patients discontinuing treatment & 3 & 16.7 & 6 & 31.6 \\
\hline Patients developing toxicity & 3 & 16.7 & 4 & 21.1 \\
\hline Patient refusal & 0 & 0 & 2 & 10.5 \\
\hline Patients receiving dose reduction & 6 & 33.3 & 3 & 15.8 \\
\hline
\end{tabular}

a carboplatin plus paclitaxel regimen, which is associated with fewer and less severe adverse events compared with cisplatin doublet treatment. The efficacy and safety of S-1 adjuvant therapy were similar or better compared with those of carboplatin plus paclitaxel. Indeed, several studies reported that S-1 administration as adjuvant chemotherapy is associated with significant survival benefits following surgically complete 
Table III. Toxicity.

\begin{tabular}{|c|c|c|c|c|c|c|}
\hline \multirow[b]{2}{*}{ Adverse events } & \multicolumn{3}{|c|}{ Carboplatin + paclitaxel $(n=19)$} & \multicolumn{3}{|c|}{$\mathrm{S}-1(\mathrm{n}=18)$} \\
\hline & G1/2 No. (\%) & G3 No. $(\%)$ & G4 No. $(\%)$ & G1/2 No. (\%) & G3 No. (\%) & G4 No. $(\%)$ \\
\hline Neutropenia & $2(11)$ & $2(11)$ & & $1(6)$ & & \\
\hline Leukopenia & $4(21)$ & & & & & \\
\hline Thrombocytopenia & $1(5)$ & & & & & \\
\hline Anorexia & & & & $2(11)$ & & \\
\hline Nausea & & & & $1(6)$ & & \\
\hline Vomiting & $1(5)$ & & & & & \\
\hline Elevation of ALT, AST & & & & $3(17)$ & & \\
\hline Elevation of bilirubin & & & & $1(6)$ & & \\
\hline Neuropathy (sensory) & $6(32)$ & & & & & \\
\hline Fatigue & $1(5)$ & & & & & \\
\hline Alopecia & $4(21)$ & & & & & \\
\hline Urticaria & & & & $2(11)$ & & \\
\hline Anaphylaxis & & & $2(11)$ & & & \\
\hline Stomatitis & & & & $1(6)$ & & \\
\hline Weight loss & & & & $1(6)$ & & \\
\hline Others & $3(16)$ & & & $5(28)$ & & \\
\hline
\end{tabular}

ALT, alanine aminotransferase; AST, aspartate aminotransferase; G, grade.

A

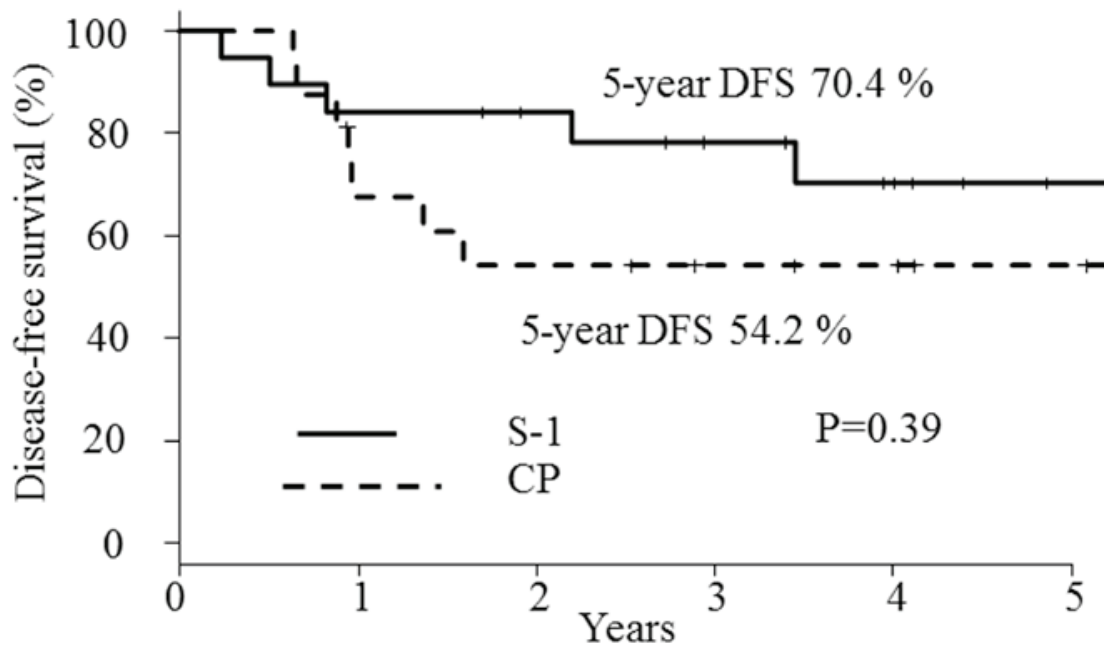

B

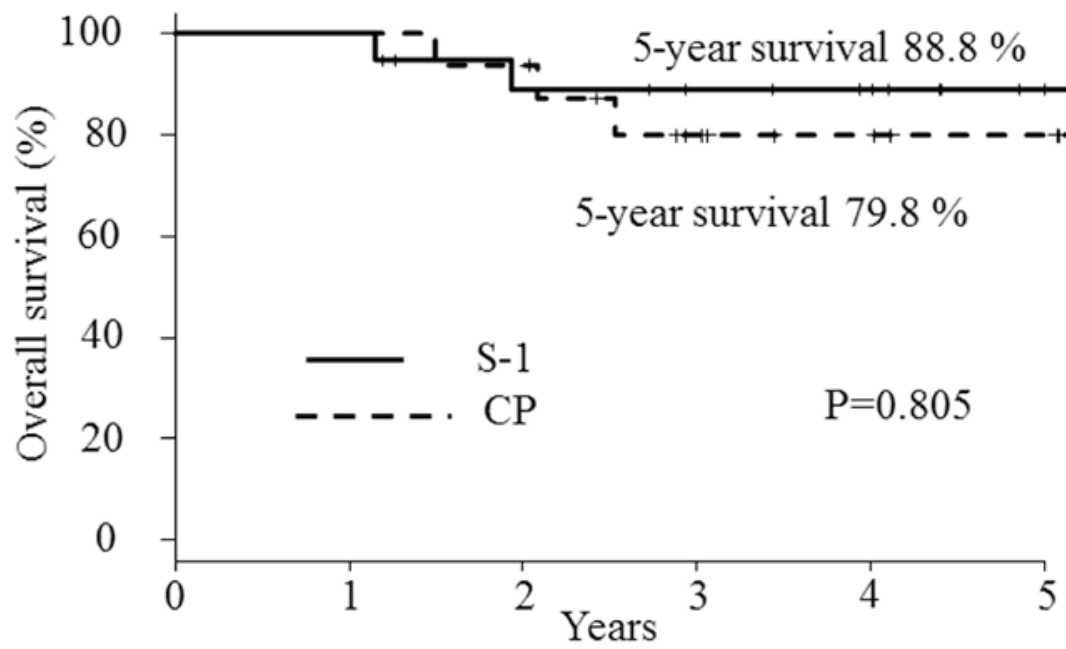

Figure 2. Kaplan-Meier estimates of (A) disease-free and (B) overall survival. DFS, disease-free survival; CP, carboplatin + paclitaxel. 
resection for gastric cancer, squamous cell carcinoma of head and neck, breast cancer and NSCLC $(19,22-24,33,34)$. The 5 -year DFS and OS were almost the same between the S-1 group and the paclitaxel plus carboplatin group. As the side effects of S-1 were tolerable, S-1 chemotherapy may be considered to be a promising adjuvant chemotherapy for patients with advanced disease who have undergone complete surgical resection.

Several studies have investigated the optimal regimen for S-1 administration. One previous study reported that a treatment schedule of a 2 -week administration followed by a 1-week interval appears more feasible and safer compared with the conventional 4-week administration followed by a 2 -week interval (35). Considering this report, a treatment schedule of 2-week administration followed by a 1-week interval was selected for the present study; although the adverse events associated with S-1 treatment were of grade 1 or 2 , and the majority were controllable, 6 patients discontinued treatment, resulting in an unsatisfactory completion rate of S-1 adjuvant therapy. Therefore, a more feasible administration schedule for S-1 as adjuvant therapy for advanced lung cancer must be developed. The main limitation of the present study was the small patient population. Further large-scale clinical trials with a longer administration period for S-1 are required. Overall, the results of the present study demonstrated that $\mathrm{S}-1$ treatment for 1 year with a 2 -week administration followed by a 1 -week interval appeared to be tolerable and safe as an adjuvant chemotherapy regimen.

In conclusion, the 2-year DFS rate as the primary endpoint was found to be acceptable. S-1 chemotherapy for patients with completely resected stage II or IIIA NSCLC was feasible and safe, and it may therefore be considered as an option for adjuvant chemotherapy in advanced NSCLC.

\section{References}

1. Asamura H, Goya T, Koshiishi Y, Sohara Y, Eguchi K, Mori M, Nakanishi Y, Tsuchiya R, Shimokata K, Inoue H, et al: A Japanese lung cancer registry study: Prognosis of 13,010 resected lung cancers. J Thorac Oncol 3: 46-52, 2008.

2. Pignon JP, Tribodet H, Scagliotti GV, Douillard JY, Shepherd FA, Stephens RJ, Dunant A, Torri V, Rosell R, Seymour L, et al: Lung adjuvant cisplatin evaluation: A pooled analysis by the LACE collaborative group. J Clin Oncol 26: 3552-3559, 2008.

3. Pisters KM, Evans WK, Azzoli CG, Kris MG, Smith CA, Desch CE, Somefield MR, Brouwers MC, Darling G, Ellis PM, et al: Cancer care onario and American society of clinical oncology adjuvant chemotherapy and adjuvant radiation therapy for stages I-IIIA resectable non-small cell lung cancer guideline. J Clin Oncol 25: 5506-5518, 2007.

4. Crinò L, Weder W, van Meerbeeck J and Felip E; ESMO Guidelines Working Group: Early stage and locally acvanced (non-metastatic) non-small-cell lung cancer: ESMO clinical practice guidelines for diagnosis, treatment and follow-up. Ann Oncol 21 (Suppl 5): v103-v115, 2010.

5. NSCLC Meta-analyses Collaborative Group, Arriagada R, Auperin A, Burdett S, Higgins JP, Johnson DH, Le Chevalier T, LePecoux C, Parmar MK, Pignon JP, et al: Adjuvant chemotherapy, with or without postoperative radiotherapy, in operable non-small-cell lung cancer: Two meta-analyses of individual patient data. Lancet 375: 1267-1277, 2010.

6. Fruh M, Rolland E, Pignon JP, Seymour L, Ding K, Tribodet H, Winton T, Le Chevalier T, Scagliotti GV, Douillard JY, et al: Pooled analysis of the effect of age on adjuvant cisplatin-based chemotherapy for completely resected non-small-cell lung cancer. J Clin Oncol 26: 3573-3581, 2008.
7. Hotta K, Matsuo K, Ueoka H, Kiura K, Tabata M and Tanimoto M: Role of adjuvant chemotherapy in patients with resected non-small-cell lung cancer: Reappraisal with meta-analysis of randomized controlled trials. J Clin Oncol 22: 3860-3867, 2004.

8. Sedrakyan A, Van Der Meullen J, O'Byrne K, Prendiville J, Hill J and Treasure T: Postoperative chemotherapy for non-small cell lung cancer: A systematic review and meta-analysis. J Thorac Cardiovasc Surg 128: 414-419, 2004.

9. Berghmans T, Paesmans M, Meert AP, Mascaux C, Lothaire P, Lafitte JJ and Sculier JP: Survival improvement in resectable non-small cell lung cancer with (neo)adjuvant chemotherapy: Results of a meta-analysis of the literature. Lung Cancer 49: $13-23,2005$.

10. Kelly K, Crowley J, Bunn PA Jr, Presant CA, Grevstad PK, Moinpour CM, Ramsey SD, Wozniak AJ, Weiss GR, Moore DF, et al: Randomized phase III trial of paclitaxel plus carboplatin versus vinorelbine plus cisplatin in the treatment of patients with advanced non-small-cell lung cancer: A southwest oncology group trial. J Clin Oncol 19: 3210-3218, 2001.

11. Ohe Y, Ohashi Y, Kubota K, Tamura T, Nkagawa K, Negoro S, Nishiwaki Y, Saijo N, Ariyoshi Y and Fukuoka M: Randomized phase III study of cisplatin plus irinotecan versus carboplatin plus paclitaxel, cisplatin plus gemcitabine, and cisplatin plus vinorelbine for advanced non-small-cell lung cancer: Four-Arm cooperative study in Japan. Ann Oncol 18: 317-323, 2007.

12. Schiller JH, Harrington D, Belani CP, Langer C, Sandler A, Krook J, Zhu J and Johnson DH; Eastern Cooperative Oncology Group: Comparison of four chemotherapy regimens for advanced non-small-cell lung cancer. N Engl J Med 346: 92-98, 2002.

13. Yamashita Y, Kataoka K, Ishida T, Matsuura M, Seno N, Mukaida H, Miyahara E, Miyata Y, Okita R, Shimizu K, et al: A feasibility study of postoperative adjuvant therapy of carboplatin and weekly paclitaxel for completely resected non-small cell lung cancer. J Thorac Oncol 3: 612-616, 2008.

14. Maruyama R, Yoshino I, Tokunaga S, Ohta M, Kato M, Yoshimine H, Yamazaki K, Nakanishi Y and Ichinose Y: Feasibility trial of adjuvant chemotherapy with paclitaxel and carboplatin after surgical resection in Japanese patients with non-small cell lung cancer: Report of the lung oncology group in kyushu (LOGIK) protocol 0501. Gen Thorac Cardiovasc Surg 56: 68-73, 2008.

15. Ichiki M, Kawasaki M, Takayama K, Ninomiya K, Kuba M, Iwami F, Miyazaki N, Oishi K, Takeo S, Aizawa H and Nakanishi Y: A multicenter phase II study of carboplatin and paclitaxel with a biweekly scheduleinpatients withadvancednon-small-cell lung cancer:Kyushu thoracic oncology group trial. Cancer Chemother Pharmacol 58: 368-373, 2006.

16. Strauss GM, Herndon JE II, Maddaus MA, Johnstone DW Johnson EA, Harpole DH, Gilenwater HH, Watson DM, Sugarbaker DJ, Schilsky RL, et al: Adjuvant paclitaxel plus carboplatin compared with observation in stage IB non-small-cell lung cancer: CALGB 9633 with the cancer and leukemia group B, radiation therapy oncology group and north central cancer treatment group study groups. J Clin Oncol 26: 5043-5051, 2008

17. Sugaya M, Uramoto H, Uchiyama A, Nagashima A, Nakanishi R, Sakata H, Nakanishi K, Hanagiri T and Uasumoto K. PPhase II trial of adjuvant chemotherapy with bi-weekly carboplatin plus paclitaxel in patients with completely resected non-small cell lung cancer. Anticancer Res 30: 3039-3044, 2010.

18. Shirasaka T, Nakano K, Takechi T, Satake H, Uchida J, Fujioka A, Saito H, Okabe H, Oyama K, Takeda S, et al: Antitumor activity of $1 \mathrm{M}$ tegafur-0.4 M 5-chloro-2,4-dihydroxypyridine-1 M potassium oxonate (S-1) against human colon carcinoma orthotopically implanted into nude rats. Cancer Res 56: 2602-2606, 1996.

19. Sakuramoto S, Ssako M, Yamaguchi T, Kinoshita T, Fujii M, Nashimoto A, Furukawa H, Nakajima T, Ohashi Y, Imamura $\mathrm{H}$, et al: Adjuvant chemotherapy for gastric cancer with S-1, an oral fluoropyrimidine. N Engl J Med 357: 1810-1820, 2007.

20. Foukakis T, Lundell L, Gubanski M and Lind PA: Advances in the treatment of patients with gastric adenocarcinoma. Acta Oncol 46: 277-285, 2007.

21. Sasako M: Surgery and adjuvant chemotherapy. Int J Clin Oncol 13: 193-195, 2008.

22. Iwamoto Y, Mitsudomi T, Sakai K, Ymanaka T, Yoshioka H, Takahama M, Yoshimura M, Yoshino I, Takeda M, Sugawara S, et al: Randomized phase II study of adjuvant chemotherapy with long-term S-1 versus Cisplatin + S-1 in completely resected stage II-IIIA non-small cell lung cancer. Clin Cancer Res 21: 5245-5252, 2015. 
23. Okumura S, Sasaki T, Satoh K, Kitada M, Nagase A, Yatsuyanagi E and Ohsaki Y: Feasibility of adjuvant chemotherapy with S-1 consisting of a 4-week administration and a two-week rest period in patients with completely resected non-small cell lung cancer. Mol Clin Oncol 1: 124-130, 2013.

24. Soh J, Okumura N, Nakata M, Nakamura H, Fukuda M, Kataoka M, Kajiwara S, Sano Y, Aoe M, Kataoka K, et al: Randomized feasibility study of S-1 for adjuvant chemotherapy in completely resected Stage IA non-small-cell lung cancer: Results of the setouchi lng cancer group study 0701. Jpn J Clin Oncol 46: 741-747, 2016.

25. TNM Classification of Malignant Tumours. Wiley-Blackwell, Oxford, 2009.

26. Calvert AH, Newell DR, Gumbrell LA, O'Reilly S, Burnell M, Boxall FE, Siddik ZH, Judson IR, Gore ME and Wiltshaw E: Carboplatin dosage: Prospective evaluation of a simple formula based on renal function. J Clin Oncol 7: 1748-1756, 1989.

27. Jellifie RW and Jelliffe SM: A computer program for estimation of creatine clearance from unstable serum creatine levels, age, sex and weight. Math Biosci 14: 17-24, 1972.

28. Cancer Therapy Evaluation Program (CTEP), Common Terminology Criteria for Adverse Events, version 3.0, DCTD, NCI, NIH, DHHS. March 31, 2003. Available at http://ctep.cancer.gov. Accessed August 9, 2006.

29. Kawamura M, Eguchi K, Izumi Y, Ymato Y, Koike T, Sakaguchi H, Hada E and Kobayashi K: Phase II trial of gemcitabine and docetaxel in patients with completely resected stage IIA-IIIA non-small-cell lung cancer. Cancer Chemother Pharmacol 60: 495-501, 2007.

30. Kanda Y: Investigation of the freely available easy-to-use software 'EZR' for medical statistics. Bone Marrow Transplant 48: 452-458, 2013
31. Vallières E, Shepherd FA, Crowley J, Van Houtte P, Postmus PE, Carney D, Chansky K, Shaikh Z and Goldstraw P; International Association for the Study of Lung Cancer International Staging Committee and Participating Institutions: The IASLC lung cancer staging project: Proposals regarding the relevance of TNM in the pathologic staging of small cell lung cancer in the forthcoming (seventh) edition of the TNM classification for lung cancer. J Thorac Oncol 4: 1049-1059, 2009.

32. Kato H, Ichinose $\mathrm{Y}$, Ohta M, Hata E, Tsubota N, Tada H, Watanabe Y, Wada H, Tsuboi M, Hamajima N, et al: A randomized trial of adjuvant chemotherapy with uracil-tegafur for adenocarcinoma of the lung. N Engl J Med 350: 1713-1721, 2004.

33. Tsukuda M, Kida A, Fujii M, Kono N, Yoshihara T, Hasegawa Y and Sugita M; Chemotherapy Study Group of Head and Neck Cancer: Randomized scheduling feasibility study of S-1 for adjuvant chemotherapy in advanced head and neck cancer. Br J Cancer 93: 884-889, 2005.

34. Shigekawa T, Osaki A, Sekine H, Sato N, Kanbayashi C, Sano H, Takeuchi H, Ueda S, Nakamiya N, Sugitani I, et al: SSafety and feasibility of adjuvant chemotherapy with S-1 in Japanese breast cancer patients after primary systemic chemotherapy: A feasibility study. BMC Cancer 15: $253,2015$.

35. Yano T, Yamazaki K, Maruyama R, Tokunaga S, Shoji F, Higashi H, Takeo S, Ichinose Y and Maehara Y; Lung Oncology Group in Kyushu (LOGIK): Feasibility study of postoperative adjuvant chemotherapy with S-1 (tegaful, gimeracil, oteracil potassium) for non-small cell lung cancer-LOGIK 0601 study. Lung Cancer 67: 184-187, 2010. 